\title{
Analysis of the Influence of Fibers on the Formability of Metal Blanks in Manufacturing Processes for Fiber Metal Laminates
}

\author{
Thomas Mennecart ${ }^{1, *}$, Soeren Gies ${ }^{1}$, Noomane Ben Khalifa ${ }^{2,3}$ and A. Erman Tekkaya ${ }^{1}$ \\ 1 Institute of Forming Technology and Lightweight Components, TU Dortmund University, 44227 Dortmund, \\ Germany; Soeren.Gies@iul.tu-dortmund.de (S.G.); Erman.Tekkaya@iul.tu-dortmund.de (A.E.T.) \\ 2 Institute of Product and Process Innovation, Leuphana University Lueneburg, 21339 Lüneburg, Germany; \\ Ben_Khalifa@leuphana.de \\ 3 Institute of Materials Research, Magnesium Innovation Centre, Helmholtz Zentrum Geesthacht, \\ 21502 Geesthacht, Germany \\ * Correspondence: Thomas.Mennecart@iul.tu-dortmund.de; Tel.: +49-231-755-2410
}

Received: 24 November 2018; Accepted: 29 December 2018; Published: 5 January 2019

\begin{abstract}
In the one-step manufacturing process for fiber metal laminate parts, the so-called in situ hybridization process, the fabrics are interacting with metal blanks. During deep drawing, the liquid matrix is injected between the metal sheets through the woven fiber layers. The metal blanks can be in contact with dry or with infiltrated fibers. The formability of the blanks is influenced by the variation of the starting time of injection. The reason for that is that, due to high contact forces, the fibers are able to deform the metal surface locally, so that movement and the strain of the blanks is inhibited. To investigate the influence of different fibers on the formability of metals, Nakazima tests are performed. In these tests, two metal blanks are formed with an interlayer of fibers. The results are compared with the formability of two blanks without any interlayer. It is shown that in with fibers between sheets, the formability decreases compared to the formability of two metal blanks without interlayers. Based on a simplified numerical model for different types of fibers, the interactions of the fibers with the metal blank are analyzed. It could be shown that the friction due to contact has more influence than the friction due to the form fit caused by the imprints.
\end{abstract}

Keywords: fiber metal laminates; deep drawing; formability

\section{Introduction}

The application of fiber metal laminates started in the aircraft industry in the 1980s with the use of Glare, as described by Vlot (2004) [1], and with the use of Arall, shown by Vogelesang (1983) [2], two products invented in the Netherlands for structural components to increase the impact behavior and to reduce fuel consumption. Today, the products with aluminum and glass fiber-reinforced plastics (Glare), or with aramid fiber reinforcement (Arall), are still used in modern aircrafts, like the Airbus A380. Non-complex and smooth curved parts are manufactured by layup techniques, where the layup is vacuum bagged, and the curing occurs in an autoclave chamber without the possibility of subsequent forming operations. In [3], Vogelesang and Gunnink described the forming of Arall parts by using folding techniques or peening. In the 1980s, the automotive industry also started to use metal-polymer-metal products for body-in-white components, to decrease the total weight, as described by Miller (1980) [4], driven by the increase of the oil prices. Semi-finished materials, i.e., by Toshiaka et al. (1983) [5], or even the process for their manufacturing were patented, i.e., by Soellart-Roelofsen and Bottema (1994) [6]. Nowadays, with the increased use of thermoplastics as matrix, fiber metal laminates become more and more advantageous to increase safety and to reduce weight. Here, two types of fiber metal laminate 
layups exist. They can be divided into the symmetrical layup with a core of fiber-reinforced plastic and two metal sheets, and the unsymmetrical layup with just one metal layer. For both types, one step as well as multiple step processes are used to manufacture 3-dimensional parts.

\subsection{Symmetrical Layup}

Several methods exist for the manufacturing of complex shaped parts. In the method shown by Wollmann et al. (2014) in [7], a semi-finished material consisting of two metal layers with a fiber-reinforced thermoplastic in-between has to be softened by heating it up. Afterwards, parts can be manufactured in a one-step forming process. Due to the soft layer in-between, there is a high risk of wrinkles. Furthermore, the thickness of the final part remains highly inhomogeneous due to the squeezing out of the polymer in regions of higher pressure as it is in zones of radii, which is shown by Behrens et al. (2014) [8].

\subsection{Unsymmetrical Layup}

For the manufacturing of fiber metal laminates with an unsymmetrical layup, one-step and multiple-step processes exist. In the investigations of Dau et al. (2011) [9], a method is shown for manufacturing unsymmetrical layups by a multiple-step process. After the forming process of a metal sheet, a softened pre-impregnated fiber reinforced plastic (prepreg) is formed into this metal sheet. The bonding occurs chemically by adhesive forces. Another process route is shown by Lee et al. (2016) [10], where a stack of prepreg and flat metal sheet is deep drawn simultaneously in one forming tool. With both methods, it could be stated that wrinkles in the flange area and material accumulation can occur, caused by the viscous and soft matrix. When forming the unsymmetrical layup sheets, a high degree of squeezing or delamination can occur. Due to a lot of challenges that are faced when manufacturing unsymmetrical fiber metal laminates, a new method was introduced by Wang et al. (2014) [11] for the purpose of handling these challenges. 3-dimensional preforms are used instead of prepregs. The 3-dimensional preform is positioned onto the formed blank. After the mold is closed, a resin is injected and infuses the fibers. The adhesive bonding is reached through chemical interactions between the surfaces of the metal and the plastic.

As the manufacturing of fiber metal laminates still faces challenges, the in situ hybridization process has been developed and introduced in [12] for the first time. In this process, conventional layers of metal sheets and woven fibers are used and stacked in the forming tool. By using a resin transfer molding device, the non-polymerized and liquid matrix is injected during forming between the sheets to infiltrate the fibers. One benefit of this method is the manufacturing of more complex shapes, due to better infiltration and the possibility of injecting until the end of the forming process to ensure a more homogeneous part thickness. As a low viscous matrix is used in this process, which is easier to squeeze out and due to the possibility to inject after the forming process has started, the fibers are able to be in a direct contact with the metal surface. In the methods mentioned above, higher viscous polymers as matrix systems are used, which have more resistance to squeezing out. Therefore, the risk of direct contact between fibers and blanks is decreased. Hence, there is a lack of knowledge about the interactions of fibers and metal surface. Therefore, the influence of the fibers on the formability of blanks needs to be investigated.

\section{Aim and Approach}

The in situ hybridization process combines two processes into one step for the manufacturing of fiber metal laminates. As shown in [12], two different strategies could be applied. Forming of fiber metal laminates can be conducted by deep drawing and resin transfer molding, or deep drawing and wet pressing. In the case of combination of deep drawing with the thermoplastic-resin transfer molding process (T-RTM), it is possible to inject independently from the deep drawing depth. The process principle is shown in Figure 1. First, to realize better adhesion, the surfaces of the blanks are pretreated by using chemical as well as mechanical methods, like the use of a primer or grinding. After staking 
the layers of metal sheet, fibers, and metal sheet in the forming tool, the forming can start and the matrix system is injected between the sheets. It is a thermoplastic matrix of highly crosslinked acrylate from Arkema S.A. (Elium). This matrix system can be processed reactively. The curing of the highly crossed acrylate takes $15 \mathrm{~min}$, when heating up the tool to $80^{\circ} \mathrm{C}$.

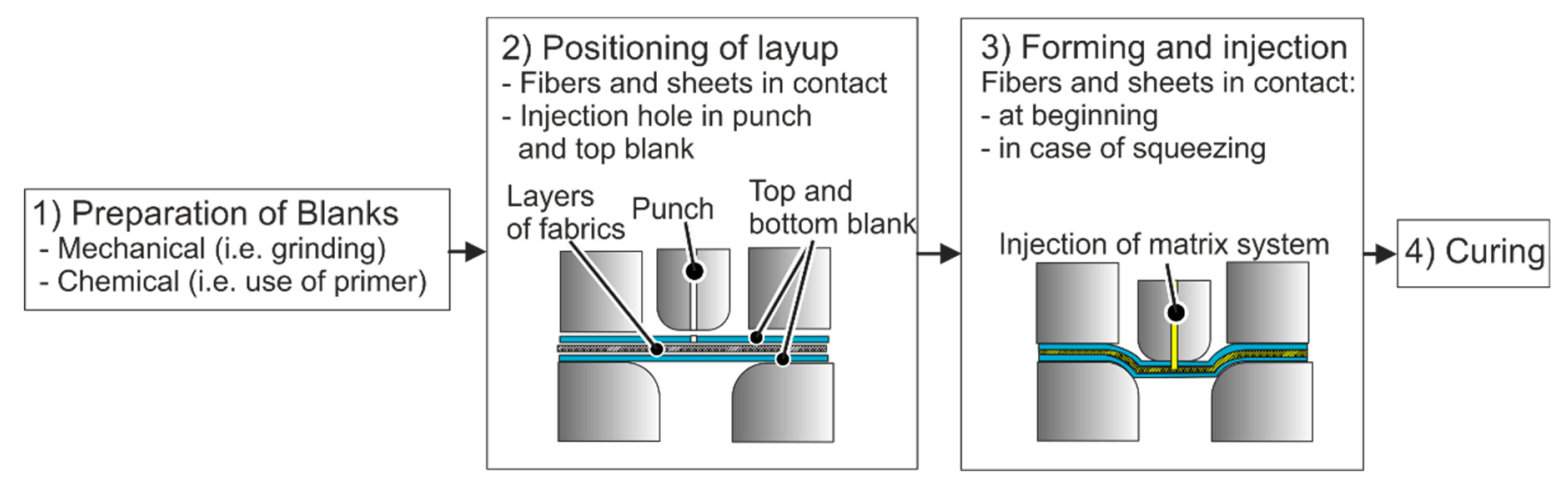

Figure 1. Process steps of the in situ hybridization process [12].

Hence, the polymer is injected between the blanks through the punch and, through a hole in one blank, a radial infiltration can be ensured. Regarding sealing conditions, it is better to start the injection with advanced deep drawing depth to realize a gap-free contact between blank and punch. This prevents a loss of polymer between blank and punch at the beginning of the deep drawing process. When starting the injection with further deep drawing depth, dry fibers get in contact with the blanks' surfaces at the beginning of the forming process. Additionally, this effect also occurs even with high contact pressure between infiltrated fibers and metal blank. A squeezing from the matrix out of the fibers can occur, so that fibers are directly in contact with the blanks as well. The direct interaction of fibers with the blanks' surfaces can influence the formability. No investigations exist regarding the direct influence of fibers on the formability of sheets. This makes it necessary to analyze the influence for the in situ hybridization process or for further fiber metal laminate manufacturing processes.

To analyze the influence of fibers on the formability of metal blank, several investigations on the laminates under different loading conditions have been performed. In a first step, Nakazima tests are performed with several interlayers. The influence of different types of fibers, in a dry or in a resin-infiltrated condition, on the formability of the metal blank, is investigated. With a modified numerical model, the experimental results and the physical reason for the influence are analyzed and validated.

\section{Materials Specifications}

For the analysis of the interaction, three types of glass fibers and one aluminum alloy are selected. The aluminum alloy $5182 \mathrm{H} 111$ with a thickness of $1.0 \mathrm{~mm}$ is a common material for body-in-white in the automotive industry. Based on the twill woven type fiber Interglas 92125 with a specific weight of $280 \mathrm{~g} / \mathrm{m}^{2}$, a twill woven glass fiber with a reduced specific weight of $80 \mathrm{~g} / \mathrm{m}^{2}$ and a plain woven fiber with a specific weight of $280 \mathrm{~g} / \mathrm{m}^{2}$ are chosen. To analyze the interaction between the fabric and the metal sheet, and to consider the fabrics in a numerical model, their geometrical parameters based on the yarn description, thread count, and fiber compaction are necessary. These parameters are described in the following sections.

\subsection{Twill Woven Fabric}

Two twill woven type of fibers are chosen. They differ in their specific weight, which leads to different geometries. The material parameters of the glass fibers can be seen in Table 1. For the heavier type, the warp yarn is carded. For both fabrics, the weights of warp and weft yarn do not differ within the fabric, with values of 204 tex and 34 tex, respectively. The thickness is measured with a micrometer gauge at five positions. The average values, named as $t_{\text {fabric }}$, are listed in Table 1 . In a fiber compaction 
test, a pressure of up to $44 \mathrm{~N} / \mathrm{mm}^{2}$ is applied on the fabric. The heavier fabric is compressed to an asymptotic stable thickness of $t^{\prime}$ fabric $=0.13 \mathrm{~mm}$. The lighter twill woven fabric reaches a compacted thickness value of $t_{\text {fabric }}^{\prime}=0.05 \mathrm{~mm}$.

Table 1. Parameters of twill woven fibers.

\begin{tabular}{|c|c|c|c|}
\hline Specific Weight in $\mathrm{g} / \mathrm{m}^{2}$ & $\begin{array}{c}\text { Yarn Description and } \\
\text { Thread Count }\end{array}$ & $\begin{array}{l}\text { Thickness } t_{\text {fabric }} \text { of } \\
\text { Fibers (Measured) }\end{array}$ & $\begin{array}{c}\text { Compacted Thickness } \\
t_{\text {fabric of Fibers }}^{\prime} \\
\text { (Measured) }\end{array}$ \\
\hline 280 & $\begin{array}{c}\text { Warp yarn: EC 9-68 tex } \\
\text { x3 t0; } 7 \text { yarn/cm } \\
\text { Weft yarn: EC 9-204 tex; } \\
6.5 \text { yarn } / \mathrm{cm}\end{array}$ & $0.23 \mathrm{~mm}$ & $0.13 \mathrm{~mm}$ \\
\hline 80 & $\begin{array}{c}\text { Warp yarn: EC 9-34 tex; } \\
12 \text { yarn/cm } \\
\text { Weft yarn: EC 9-34 tex; } \\
11.4 \text { yarn/cm }\end{array}$ & $0.07 \mathrm{~mm}$ & $0.05 \mathrm{~mm}$ \\
\hline
\end{tabular}

Figure 2a shows, schematically, the geometrical structure of the twill woven fabric. In Figure $2 b, c$, the cross-sections of the structure are shown for an unloaded and a loaded condition of the fibers. Due to a rearrangement of the filaments into free spaces under load, the compacted thickness can reach low values, which depends on the geometry (specific weight) and the thread count of yarns.

a) Twill woven type

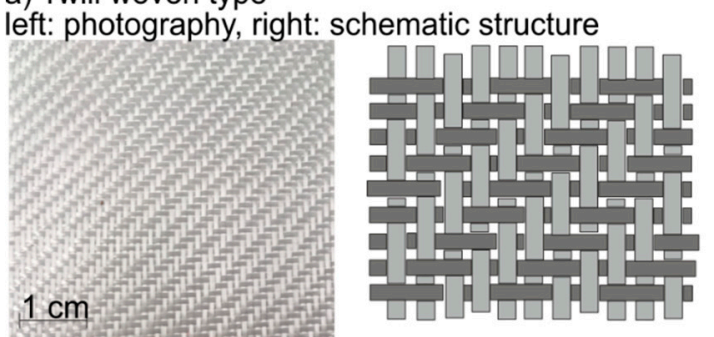

b) Schematic cross section of twill woven fabric

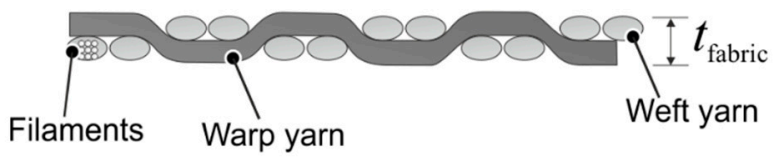

c) Schematic cross section of twill woven fabric under loading condition

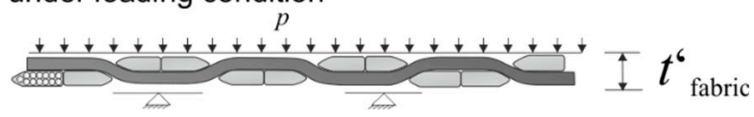

Figure 2. Geometry of twill woven fiber:

(c) cross-section loaded.

(a) structure; (b) cross-section unloaded;

\subsection{Plain Woven Fabric}

A plain woven glass fiber type with a specific weight of $280 \mathrm{~g} / \mathrm{m}^{2}$ is chosen. In Table 2, parameters for the description of the fabric type are given. The measured initial thickness reaches a value of $t_{\text {fabric }}=0.23 \mathrm{~mm}$. In the fiber compaction test, a thickness of $t_{\text {fabric }}^{\prime}=0.13 \mathrm{~mm}$ is measured.

Table 2. Parameters of plain woven fibers.

\begin{tabular}{|c|c|c|c|}
\hline $\begin{array}{l}\text { Specific Weight } \\
\text { in } \mathrm{g} / \mathrm{m}^{2}\end{array}$ & $\begin{array}{l}\text { Yarn Description and } \\
\text { Thread Count }\end{array}$ & $\begin{array}{l}\text { Thickness } t_{\text {fabric }} \text { of } \\
\text { Fibers (Measured) }\end{array}$ & $\begin{array}{c}\text { Compacted Thickness } t_{\text {fabric }}^{\prime} \\
\text { of Fibers (Measured) }\end{array}$ \\
\hline 280 & $\begin{array}{c}\text { Warp yarn: EC 11-204 } \\
\text { tex, } 8 \text { yarn/cm } \\
\text { Weft yarn: EC } 11-204 \text { tex, } \\
6 \text { yarn } / \mathrm{cm}\end{array}$ & $0.23 \mathrm{~mm}$ & $0.13 \mathrm{~mm}$ \\
\hline
\end{tabular}

Figure 3a shows schematically the geometrical structure of the plain woven fabric. Due to the different type of weave compared to the twill weaving technique, the waviness ratio of the plain woven fabric is higher. In Figure $3 b, c$, the cross-sections of the structure are shown for an unloaded and a loaded condition of the fibers. The waviness of the fabric occurs after each yarn, so that the drapability is lower than for fabric woven in twill technique. 
a) Plain woven type

left: photography, right: schematic structure
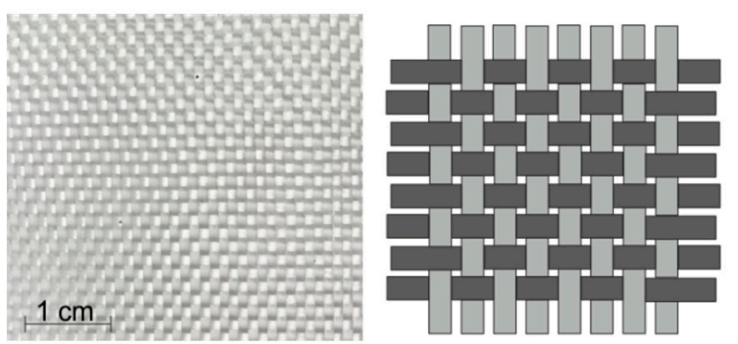

Figure 3. Geometry of plain woven fiber: cross-section loaded. b) Schematic cross section of plain woven fabric

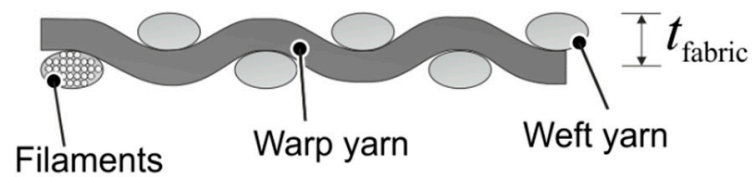

c) Schematic cross section of plain woven fabric under loading condition

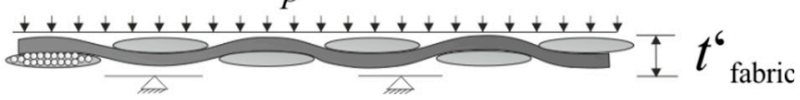

(a) structure; (b) cross-section unloaded; (c)

\section{Nakazima Tests}

\subsection{Experimental Setup}

To describe the formability of metal blanks, adapted Nakazima tests are performed (Figure 4). Based on the standard DIN EN ISO 12004-2, in which the formability of one sheet is analyzed, two sheets are stretch-formed. Several setups (listed below) are used to investigate the influence of the layer in between on the formability:

- Two sheets without layer in between

- Two sheets with lubricant in between (Grease, NLGI2 class)

- Two sheets with dry fibers in between (plain and twill woven)

- Two sheets with infiltrated (matrix system Elium 150) fibers in between (twill woven)

a)

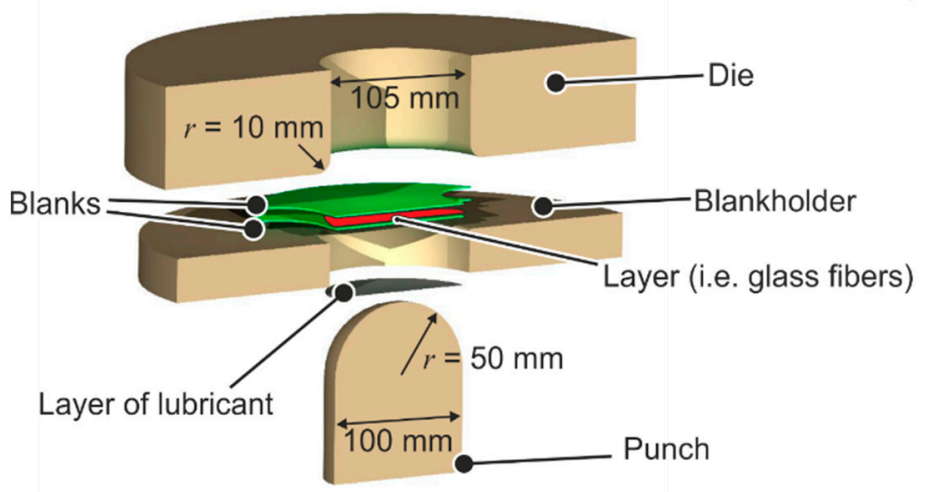

b)
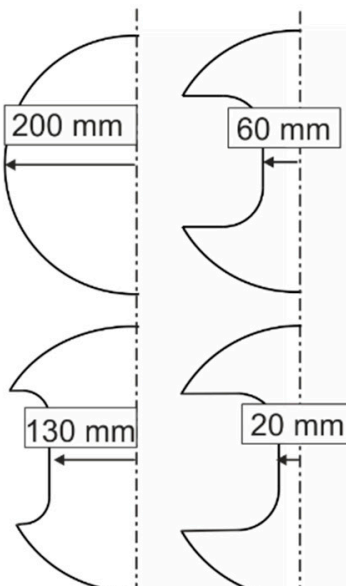

\section{Process parameters:}

Based on standard DIN EN ISO 12004-2

Blankholder force $F_{\mathrm{NH}}=800 \mathrm{kN}$

Radius specimen $r_{\text {spec }}=30 \mathrm{~mm}$

Punch velocity $v_{\text {punch }}=1,5 \mathrm{~mm} / \mathrm{s}$

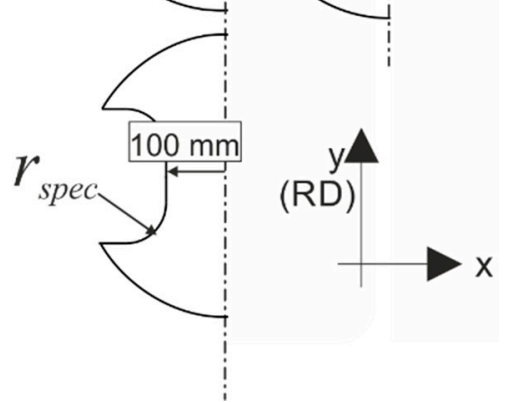

Figure 4. (a) Nakazima test setup; (b) specimen geometries.

The diameter of the fabrics is $100 \mathrm{~mm}$, which also corresponds to the punch diameter, so that the fibers are not clamped by the blankholder force. The layers are positioned in $0^{\circ} / 90^{\circ}$ and in $-45^{\circ} / 45^{\circ}$ 
to the rolling direction of the metal sheet (RD, y-axis Figure $4 b$ ). The experimental setup is shown in Figure $4 \mathrm{a}$. With a punch speed of $v_{\text {punch }}=1.5 \mathrm{~mm} / \mathrm{s}$ and a blankholder force of $F_{\mathrm{BH}}=800 \mathrm{kN}$, the specimens are drawn until cracking occurs in the metal blank. In Figure $4 \mathrm{~b}$, the used specimen geometries for the different stress states are shown. To achieve different stress states, the width of the specimen is reduced from $200 \mathrm{~mm}$ (biaxial) to $20 \mathrm{~mm}$ (uniaxial).

\subsection{Results}

The first and the second principal strain of the top sheet are measured by an optical strain measurement system. Figure $5 \mathrm{a}-\mathrm{c}$ shows the forming limit curves (FLC) for different setups. In Figure 5a, it can be seen that the FLC for the setups without layer and lubricant as layer are nearly identical. The friction condition between the sheets shows no influence on the formability. With a layer of fibers between the sheets, the formability decreases significantly, especially for the specimen with a width of $200 \mathrm{~mm}$ (biaxial stress state) and $130 \mathrm{~mm}$. For these stress conditions, a drop of up to $50 \%$ of the first and the second principal strains can be observed. With a decrease of the specimens' widths, the drop decreases to nearly $10 \%$ for the specimen with the width of $20 \mathrm{~mm}$. In the case of infiltration of the fibers with the matrix system (Elium 150) with a dynamic viscosity of $100 \mathrm{mPas}$, the strains do not differ significantly from the strains of the blanks with dry fibers in between. From this comparison, it can be concluded that the liquid does not affect the formability, but the formability is affected by the interaction between fibers and blanks. In Figure 5b, the different types of fibers in the direction of $0^{\circ}$ to the specimen orientation are compared. The fabrics (plain and twill woven types) with the specific weight of $280 \mathrm{~g} / \mathrm{m}^{2}$ affect the strain of the blanks in the $200 \mathrm{~mm}$ specimen more than the fabric with a very low specific weight of $80 \mathrm{~g} / \mathrm{m}^{2}$. The drop for this specimen is $28 \%$ compared to the drop of $50 \%$ with the heavier fabrics. It can be concluded that the specific weight has an influence on the decrease of strains. Furthermore, the type of weaving fibers does not affect the formability as it is done by the specific weight. In the case where the fibers are orientated in $45^{\circ}$ to the specimen direction (Figure $5 \mathrm{c}$ ), slight differences can be observed for the specimen with the width of $20 \mathrm{~mm}$. Here, the first and the second principal strains can reach slightly higher $\left(22 \%\right.$ for $\varepsilon_{2}$ and $12 \%$ for $\varepsilon_{1}$ ) values with fabrics orientated in $45^{\circ}$. It can be concluded that fibers lying between two metal sheets in an infiltrated or un-infiltrated state have a significant influence on the formability of the metal sheet for the region of the biaxial stress state. The loss of formability for the specimen with the width of $20 \mathrm{~mm}$, up to the width of $100 \mathrm{~mm}$ (nearly uniaxial strain state), is less than the loss of formability for the strain states in the area of positive second principal strains. Especially the different diameters of the yarns, which result in differences in specific weights, show the highest influence as it can be seen in Figure $5 b$. The liquid and the orientation of the fibers do not influence the maximum strain significantly.

The strain distribution can give first indications for the lower forming limit. In the center of Figure 6, one specimen, including the dry layer of fabric after the Nakazima test, is presented. The strain distribution of the blank can be seen on the left-hand side for two different twill woven fabrics with different specific weights. Here, a typical local strain distribution in a cross shape can be detected for the fabrics with higher specific weight. This localization of strain occurs after the cracking of the fibers. After the generation of cracks in the fibers, the metal blanks are able to localize their deformation in these zones. Furthermore, the fibers are able to deform the surface of the metal blanks in direction of thickness, so that an imprint of the fibers' geometry can be detected on the surface (Figure 6 bottom detail). 
a)

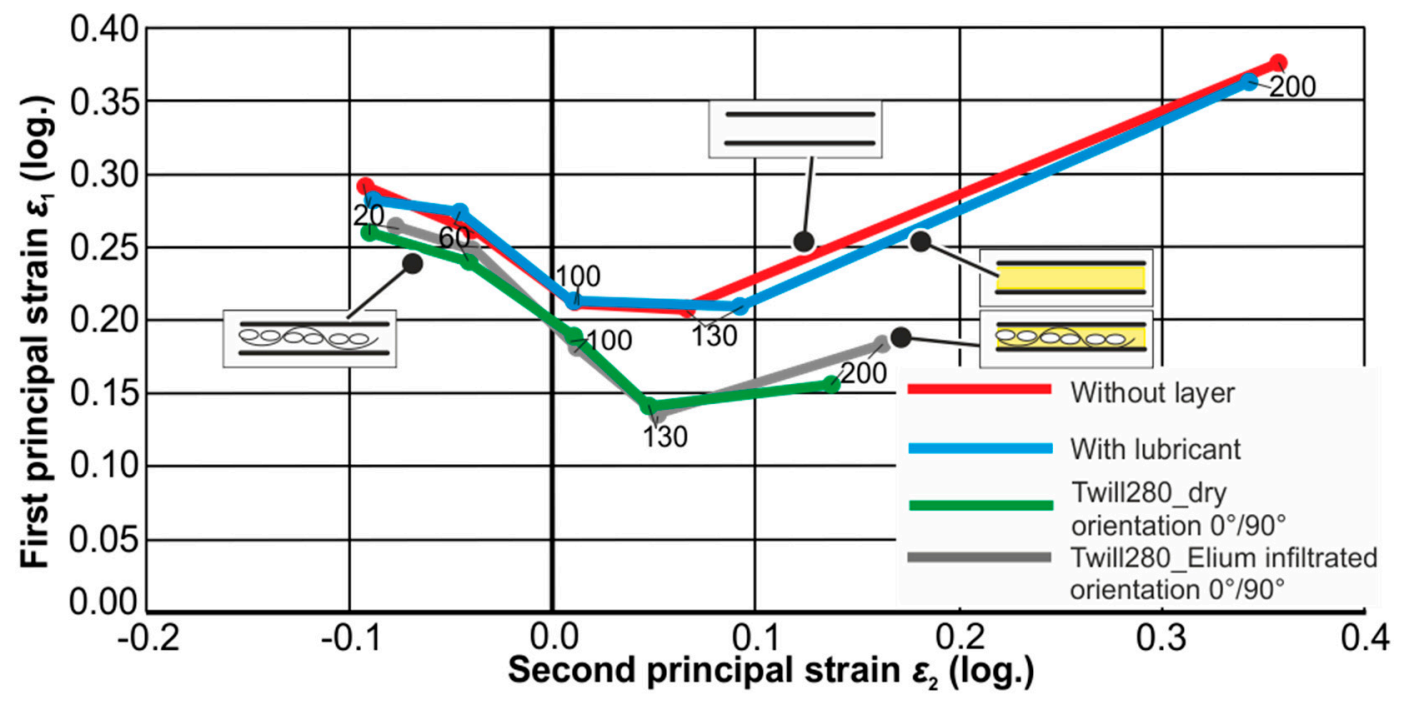

b)

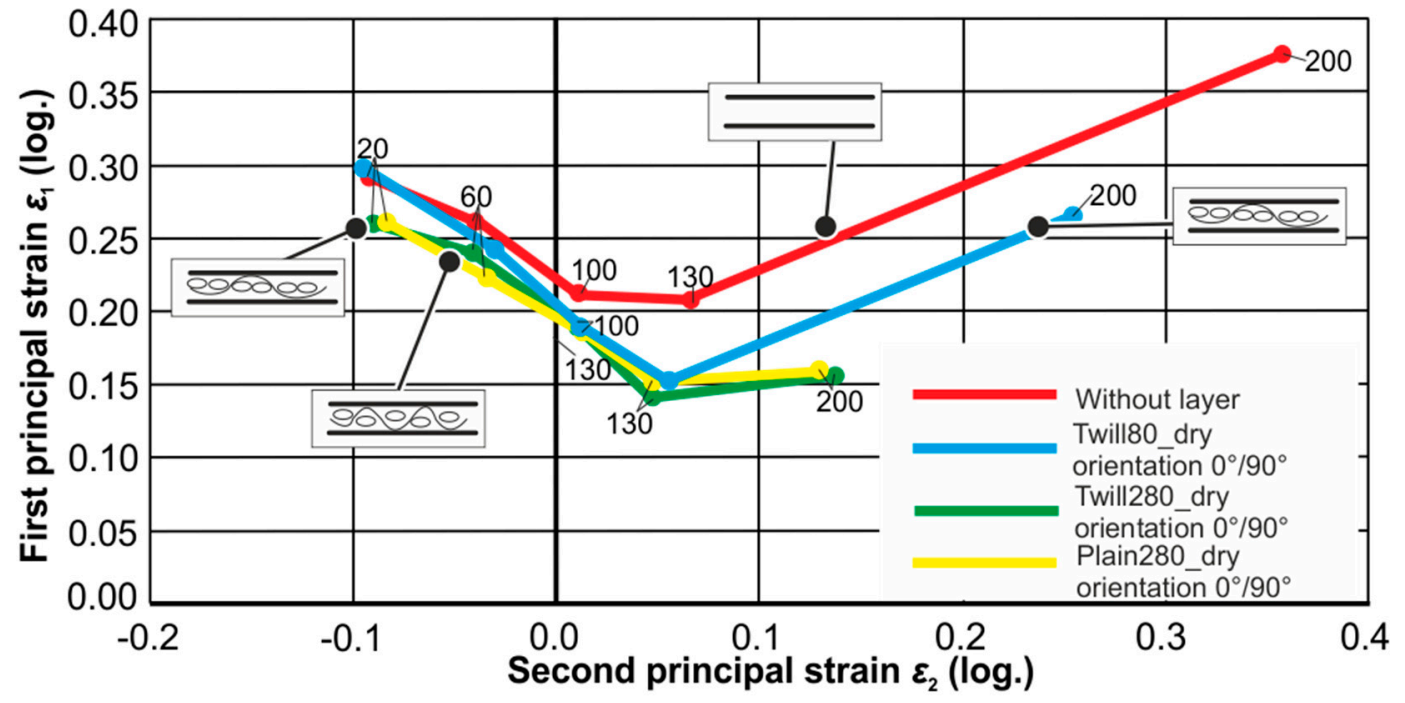

c)

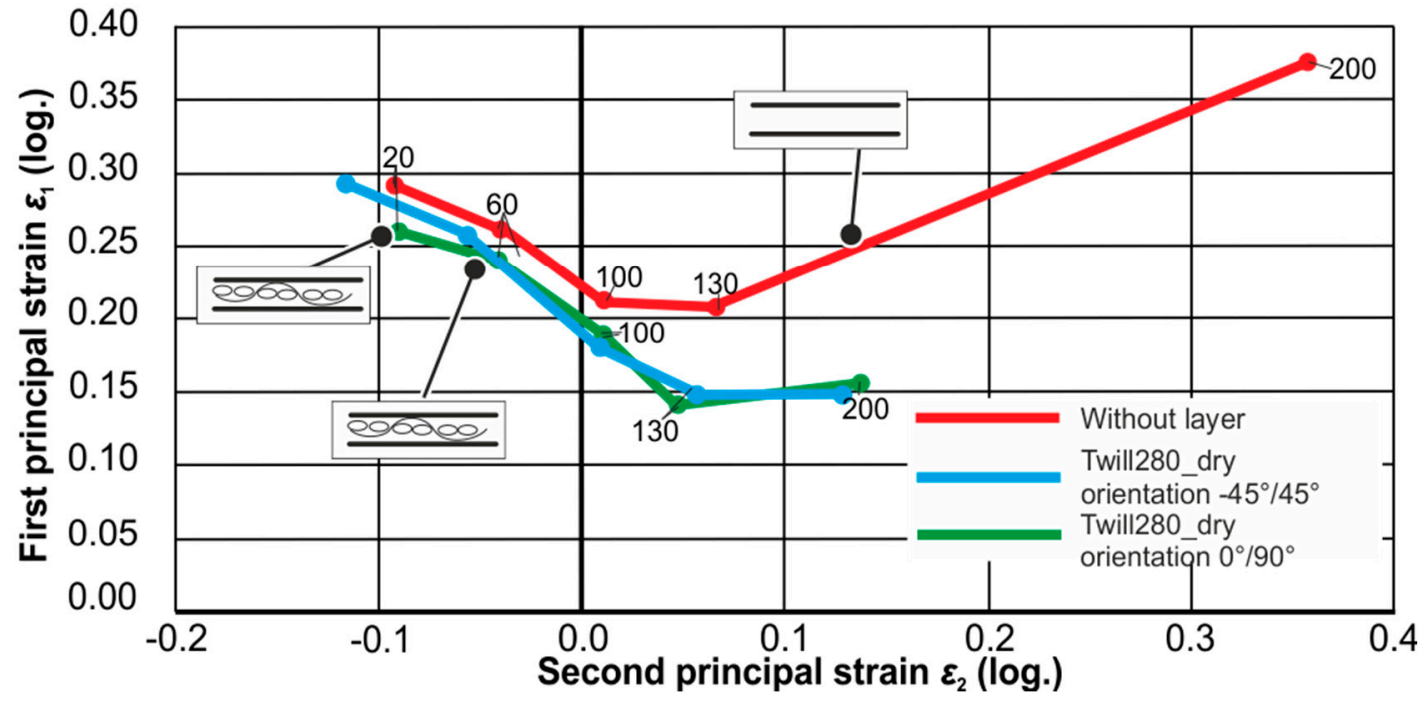

Figure 5. Forming limit curves (FLC) for different layups: (a) layup without layer compared with different layers and lubrications; (b) without layer compared with different fibers in $0^{\circ}$ orientation; (c) without layer compared with Twill280 in two fiber orientations. 


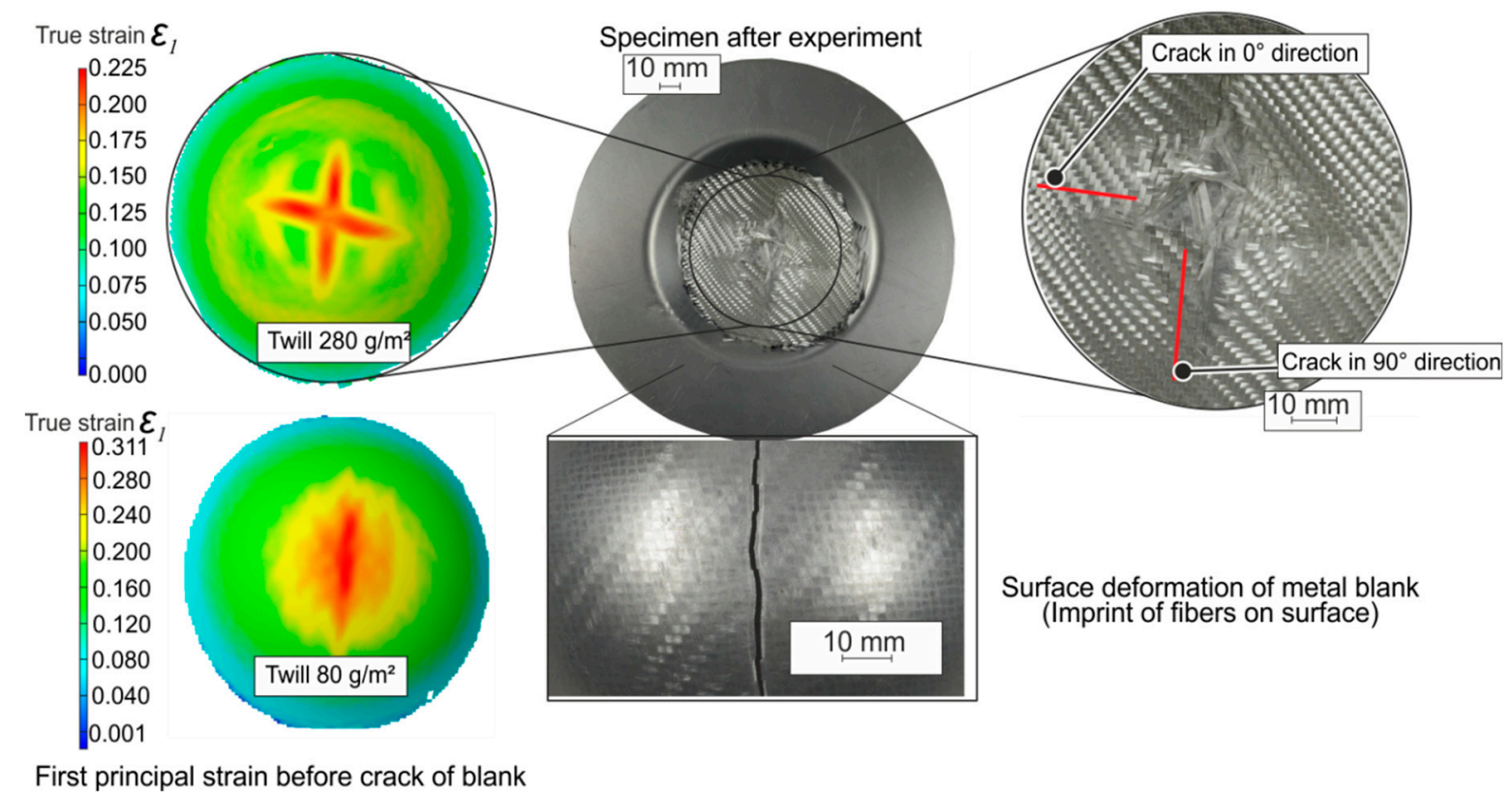

Figure 6. Comparison of strain distribution and fiber (Twill $280 \mathrm{~g} / \mathrm{m}^{2}$ ) fracture in Nakazima test specimen.

One reason for the decrease of formability when a metal surface interacts with a dry or infiltrated fabric is the hindering of deformation by friction. Besides coulomb friction, the imprint of the fibers creates a form-fit connection in the contact zone, which is the second reason for the inhibition. This can be seen in Figure 6, in which the imprint and the characteristic localization of strain are shown.

Figure 7 shows, schematically, the physical explanation for the decrease of strain. When using a woven fabric, the orientations of the warp and weft fibers are in $0^{\circ}$ and $90^{\circ}$. The best draping behavior of a twill woven type can be reached when a round punch penetrates the fabric and the warp and weft fibers can rotate and move outwards. Thereby, a rotation in the crossing points can occur, so that that the angle $\alpha$, starting with a value of $90^{\circ}$, becomes different after rotation (angle $\beta$ ). After the locking angle is reached, the fabrics start to wrinkle. The movement of the fiber is inhibited when the fiber is positioned between both blanks. Thus, the typical draping cannot take place anymore. Under loading conditions, when a normal load is applied, the rovings are able to fill free spaces in the woven structure, by changing their round shape to more elliptic or even rectangular shapes. From a certain point of rearrangement, and due to the normal load applied, the woven structure is imprinted on the metal surface. In the case of positive uniaxial strains in in-plane direction (Figure $7 \mathrm{~b}, \mathrm{c}$ ), the hindering of strain of the metal blank is caused by two effects: On one hand, there is a form-fit between fibers and blanks. Due to very low elongation of the fiber, the strain of the blank is hindered. On the other hand, there is the normal friction between the fabric and the blank. Here, just the fibers in direction of the strain can transfer the friction force. Fibers are just able to transfer tensile forces in the direction of fibers. That is why there is nearly no change in strain in the FLCs in the region of negative strains. In case of biaxial stresses, there is one additional aspect for the inhibition of strain: the friction in the direction of the weft fibers. 
a) Draping and reorientation behaviour of fibers
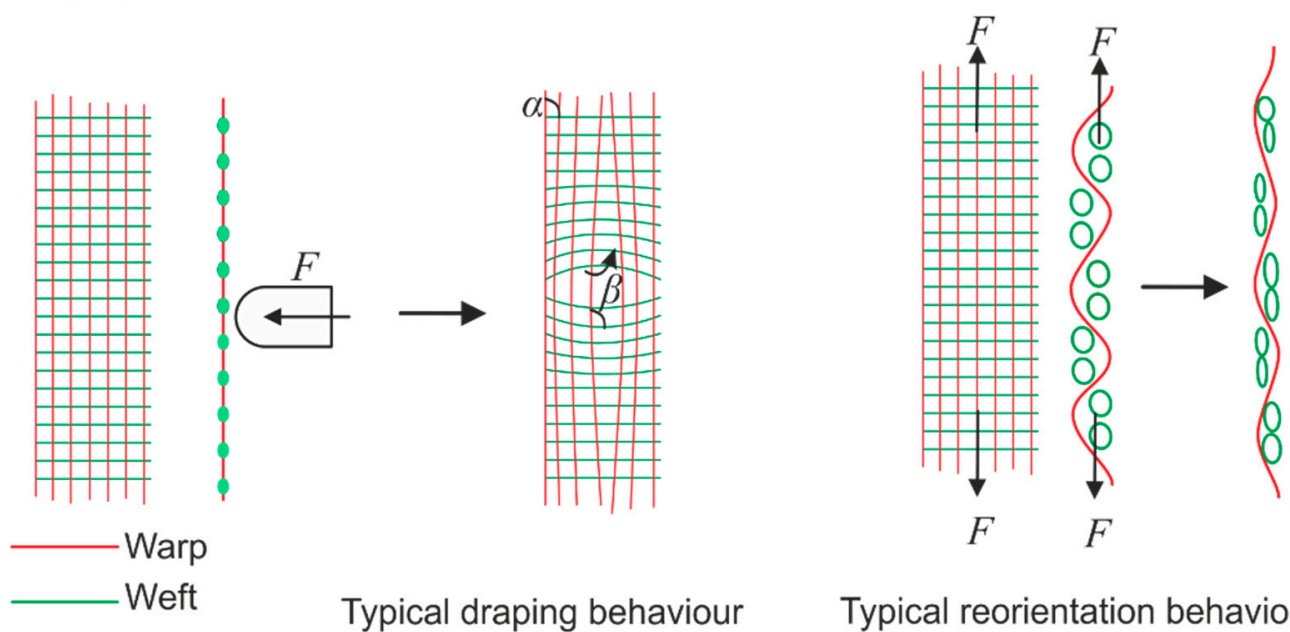

Typical draping behaviour

Typical reorientation behaviour

b) Influence of strains by fabrics under loading condition for uniaxial stress state

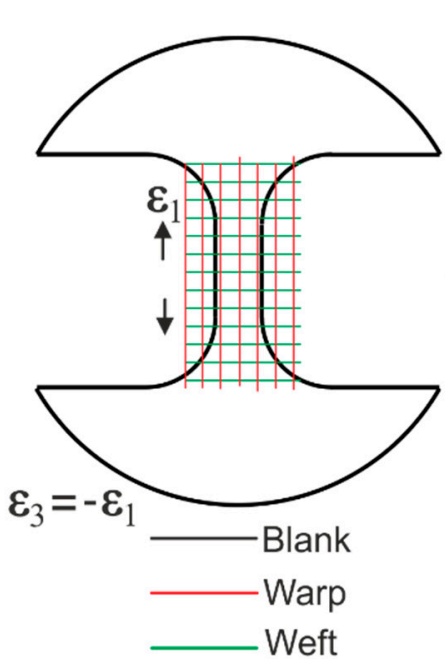
Hindering of strain:

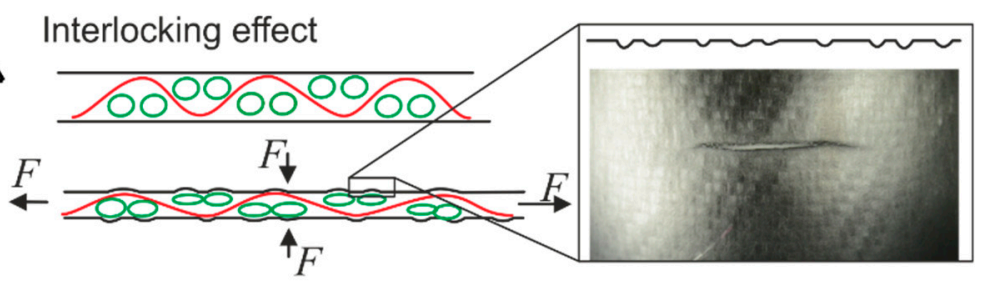

+ Friction in warp direction

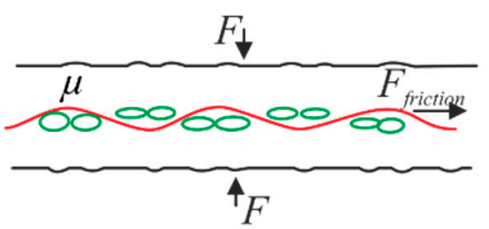

c) Influence of strains by fabrics under loading condition for biaxial stress state

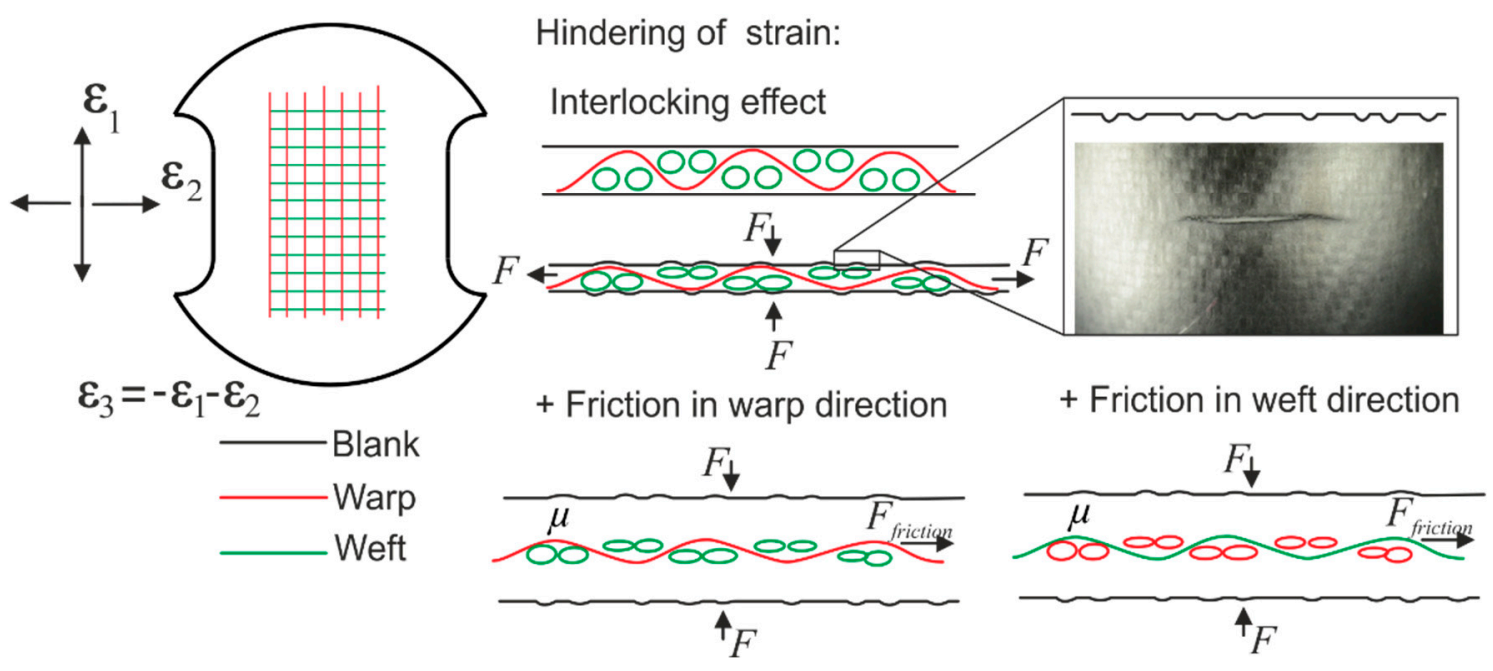

Figure 7. (a) Draping and reorientation behavior of fibers; (b) influence of fibers under normal load in uniaxial stress state; (c) influence of fibers under normal load in biaxial stress state. 
Hence, for the widths from $130 \mathrm{~mm}$ up to $200 \mathrm{~mm}, 100 \%$ more of the fibers are influencing the strain of the metal compared to the uniaxial stress state or states with compressive strains. The loss of the first and second principal strains for the specimens with the widths of $20 \mathrm{~mm}$ up to $100 \mathrm{~mm}$ is nearly the same. In biaxial stress states, the strain in thickness direction is two times higher as for the directions of stresses, as known from the deviatoric stress and the Levy-Mises equation.

Besides the stress state, the shape of the fibers, which affects the size of the imprints, shows an influence on the formability as well.

\section{Numerical Investigations}

To analyze the influence of the fibers' shapes on the form-fit connection of a metal blank in the in situ hybridization process, a simplified model is used. As shown in Figure 8a, the surface of a woven fiber is idealized. Based on fibers' parameters in the compacted states (Tables 1 and 2) the thickness of the warp and the weft yarn can be calculated. The mass $m_{\text {yarn }}$ of one yarn can be calculated with the cross-section area $A_{\text {yarn, }}$ the length $L_{\text {yarn, }}$ and the density $\rho_{\text {yarn }}$ to

$$
m_{\text {yarn }}=A_{\text {yarn }} \cdot L_{\text {yarn }} \cdot \rho_{\text {yarn }} \cdot
$$

a)

b)

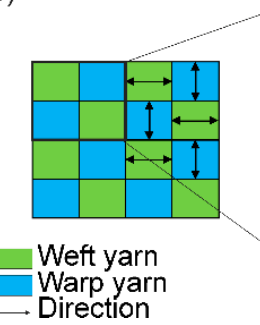

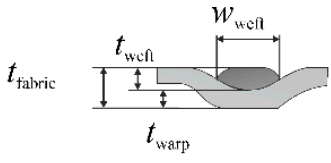

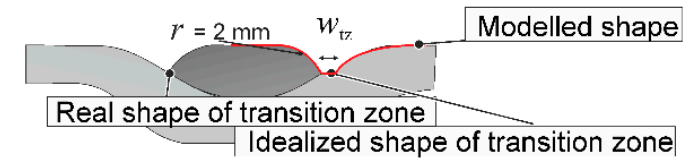

Idealized shape of transition zone

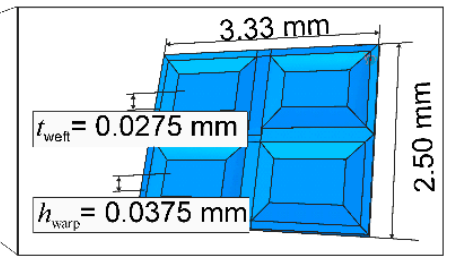

c)

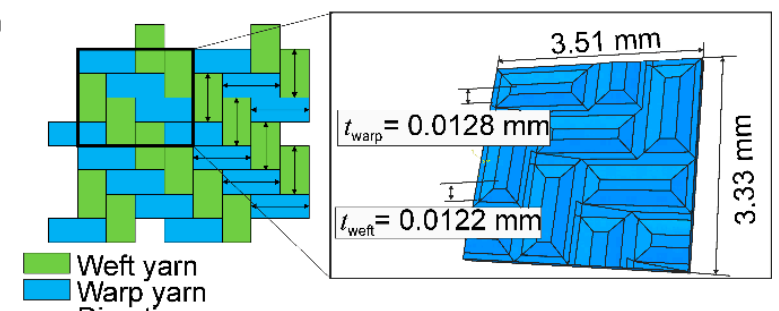

d)

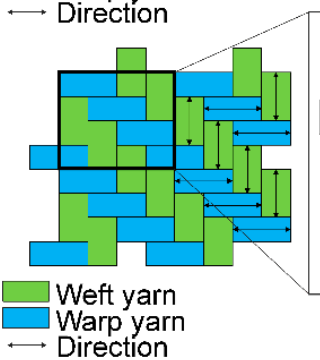

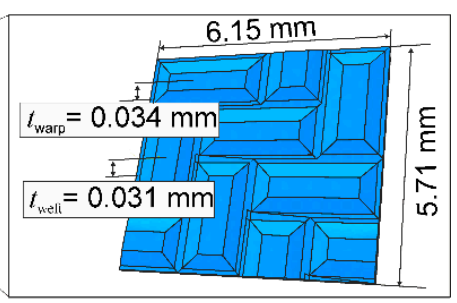

$E$
$E$
$\bar{T}$
Li

Figure 8. Simplified surface structure of the fabric for numerical modeling: (a) structural dimensions of woven fibers; (b) dimensions of plain woven type shape; (c) dimensions of $80 \mathrm{~g} / \mathrm{mm}^{2}$ twill woven type shape; and (d) dimensions of $280 \mathrm{~g} / \mathrm{mm}^{2}$ twill woven type shape.

Due to the proportionality of mass and cross-section area, and with the parameter thread count $n$ (yarn per $\mathrm{cm}$ ), which corresponds to the inverse of the yarn's width $w$, the thickness $t$ of the weft and the warp yarns can be calculated with

$$
t_{\text {warp }}^{\prime}=\frac{n_{\text {warp }} \cdot A_{\text {warp }}}{\left(n_{\text {warp }} \cdot A_{\text {warp }}\right)+\left(n_{\text {weft }} \cdot A_{\text {weft }}\right)} \cdot t^{\prime} \text { fabric }
$$

and

$$
t^{\prime}{ }_{\text {weft }}=t_{\text {fabric }}^{\prime}-t^{\prime}{ }_{\text {warp }} \text {. }
$$

With the values of the yarns' thicknesses $t^{\prime}$ warp and $t_{\text {weft }}$, the smallest repeating pattern can be modeled for the plain woven (Figure 8b), the lighter twill woven (Figure 8c), and the heavier one (Figure 8d). According to the specific weight of the fabrics and their thread counts, the thicknesses of their yarns differ from low values of $t^{\prime}{ }_{\text {weft }}=0.0122 \mathrm{~mm}$, for the lighter twill woven fabric, up to $t^{\prime}{ }_{\text {warp }}=0.0375 \mathrm{~mm}$ for the plain woven fabric. To avoid difficulties in meshing of the fabrics, the sharp 
transition zone is mitigated. An idealized transition zone (Figure $8 \mathrm{a}$ ) with a width $w_{\text {tz }}$ of $0.2 \mathrm{~mm}$ is chosen, which corresponds to the maximum element size of the meshed fabric.

The components and boundary conditions of the numerical model are shown schematically in Figure 9. An explicit model with the use of mass scaling is used in Abaqus. A metal blank of $7 \times 7 \mathrm{~mm}^{2}$ with a thickness of $1 \mathrm{~mm}$ is meshed with elements of different lengths. In the contact area of blank and fiber, the blank is meshed with solid elements called C3D8R with a length of $0.033 \mathrm{~mm}$. In the contact area of blank and punch, the blank is meshed with solid elements called C3D8R with a length of $0.2 \mathrm{~mm}$. A coulomb friction coefficient of $\mu=0.2$ is used, which is the average value of the friction between E-glass fibers and aluminum. For the purpose of time efficiency in simulation time, a simple material model is used. The blank is modeled as elastic-plastic material with the material parameters of the AA5182 H111 alloy, which can be seen in Figure 9c. Although this material model is a simple one, it is suitable in terms of the verification of the physical explanation. Furthermore, it is suitable for the analysis of the influence of the fibers' geometry on the form-fit between metal and fibers. The punch and the fiber are modeled as undeformable parts using the tie rigid body option to maintain the calculation of their strains. In the first simulation step, with a time step of $0.01 \mathrm{~s}$, a pressure is applied on the sheet by the punch. In the second simulation step, the whole sheet is moved in the $\mathrm{x}$-direction for a displacement of $1.5 \mathrm{~mm}$, by using the velocity boundary condition with a speed of $v=500 \mathrm{~mm} / \mathrm{s}$ (Figure 9b). For the determination of the force related to the form fit, the output $C F_{\mathrm{N}}$ parallel to the fibers surface (x-direction) is used. This is a reaction force in the contact zone. This force is compared with the reaction force induced by shear which is caused by the coulomb friction. In Abaqus, this force is called $C F_{\mathrm{S}}$.

a)
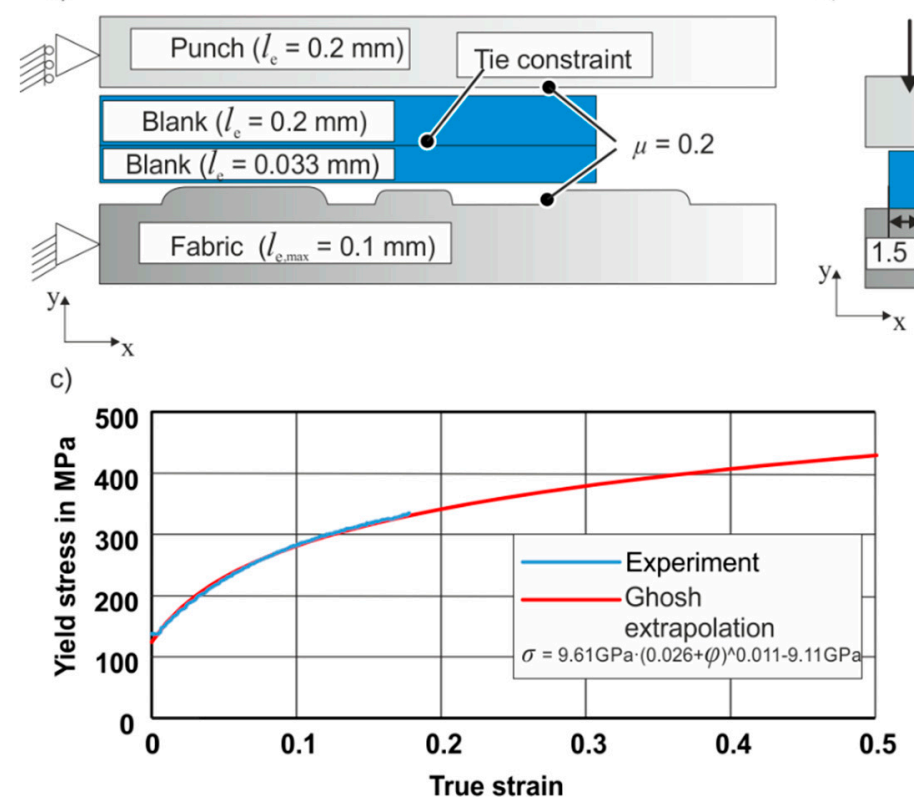

b)

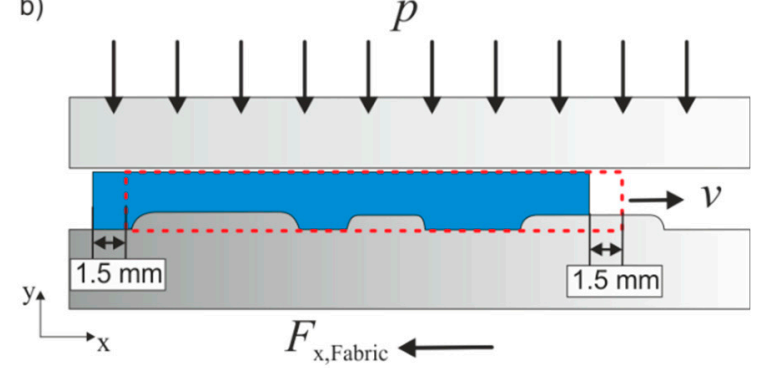

Figure 9. Simplified numerical model: (a) initial state; (b) simulated process with pressure and displacement; and (c) material and simulation process parameters.

For the verification of the numerical model, the depth of the imprints of the simulation with the depths measured from the experimental compression tests (twill woven fabric with the specific weight of $280 \mathrm{~g} / \mathrm{m}^{2}$ ) are compared (Figure 10). With the increasing of load, the filling of the transition zones (Figure $8 \mathrm{a}$ ) increases. For the load of $400 \mathrm{MPa}$, the transition zone is completely filled by the aluminum material. The depths in the experiments are slightly lower, but the results correspond well, in general. 


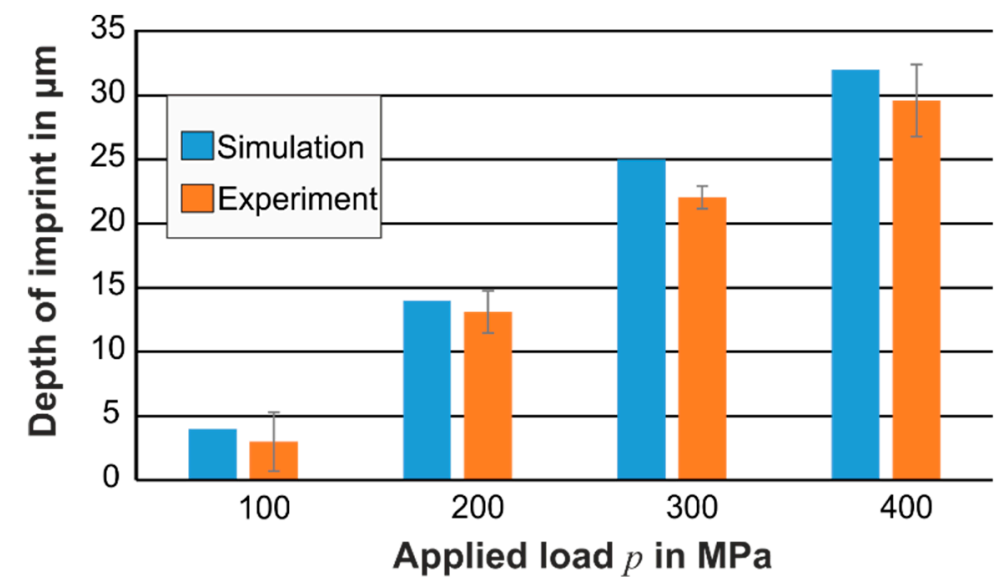

Figure 10. Depth of imprints in AA5182 surface caused by twill woven $\left(280 \mathrm{~g} / \mathrm{m}^{2}\right)$ fabrics—comparison between simulation and experiments.

\section{Results}

The diagrams in Figure 11a-c show the influence of the fibers' shapes and orientations on the maximum reaction forces $C F_{\mathrm{S}}$ and $C F_{\mathrm{N}}$. Furthermore, they show the ratio $r$ of the friction coefficients caused by the form-fit $\left(\mu_{\mathrm{CFN}}\right)$ and caused by shear $\left(\mu_{\mathrm{CFS}}\right)$. The coefficient $\mu_{\mathrm{CFS}}$ remains constant with a value of 0.2 , while the friction coefficient $\mu_{\mathrm{CFN}}$ is proportional to the reaction force $C F_{\mathrm{N}}$. The highest friction coefficient $\mu_{\mathrm{CFN}}$ is reached when movement of the blank starts (sticking condition). The ratio

$$
r=\frac{u_{\mathrm{CFN}}}{u_{\mathrm{CFS}}}
$$

indicates the influence of the form-fit on the reaction force compared to the reaction force caused by the applied coulomb friction. The force $C F_{\mathrm{S}}$ caused by the coulomb friction increase linearly with the applied load. Small differences in the contact areas for the different fibers lead to very slight differences in these forces. The differences are not visible in the diagrams, so that the three curves seem to fit to each other. In Figure 11a, for the fiber orientations of $0^{\circ}$ and $90^{\circ}$, it can be seen that the ratio $r$ does not exceed 0.15 for the light twill woven fabric. For the heavier fabric, twill and plain woven, the ratio reaches values up to 0.225 . In the case of load peaks up to $220 \mathrm{MPa}$, more than $20 \%$ of the reaction forces needed for the beginning of movement are caused by the form-fit effect. After the maximum is reached, the ratio decreases, and the inhibition of movement caused by the coulomb friction increases. It can be seen that the twill and plain woven fibers have their maximum with the same load applied. This corresponds well to the fact that the interlocking is driven by the depth of the valleys between warp and weft roving, which is nearly the same for these two fabrics. The ratio for the plain woven type reaches slightly higher values. In Figure $11 \mathrm{~b}$, for the fiber orientations of $-45^{\circ}$ and $+45^{\circ}$, the ratio for the plain woven type increases up to a value of $35 \%$. Due to the geometry, there is more contact surface for the interlocking effect than for the twill woven type. For the twill woven types, the ratio increases up to values of $24 \%\left(280 \mathrm{~g} / \mathrm{m}^{2}\right)$ and $17 \%\left(80 \mathrm{~g} / \mathrm{m}^{2}\right)$, which is a slight increase compared to the other fiber orientation. This can be seen also in Figure 11c, where both fiber orientations for the twill woven type are shown. An increase of $5 \%$ caused by interlocking can be observed, in case the fibers lie at an angle of $45^{\circ}$. In all cases, the contact forces caused by the interlocking $C F_{\mathrm{N}}$ increase with an increasing applied load. The slopes of the curves decrease with higher normal load, due to the fact that the grade of the filling the valleys between the warp and the weft rovings increases. In the $0^{\circ} / 90^{\circ}$ orientation in Figure 11a, the values of the force $C F_{\mathrm{N}}$ for both $280 \mathrm{~g} / \mathrm{m}^{2}$ fabrics nearly fit to each other. Due to the same specific weight, the width of the rovings and the depth of the transition zones are nearly identical. 
a)

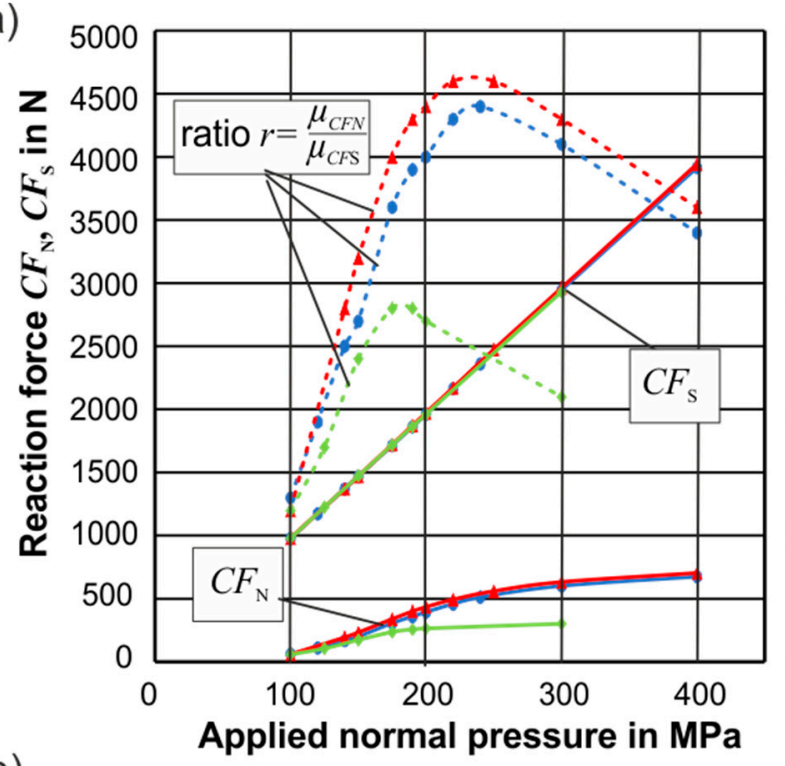

b)

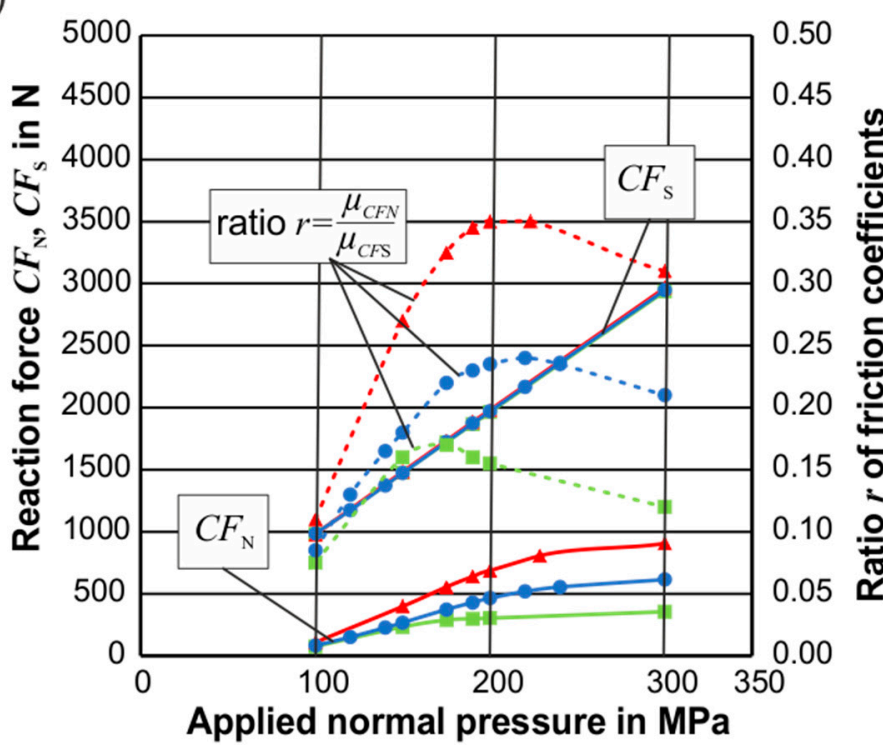

c)

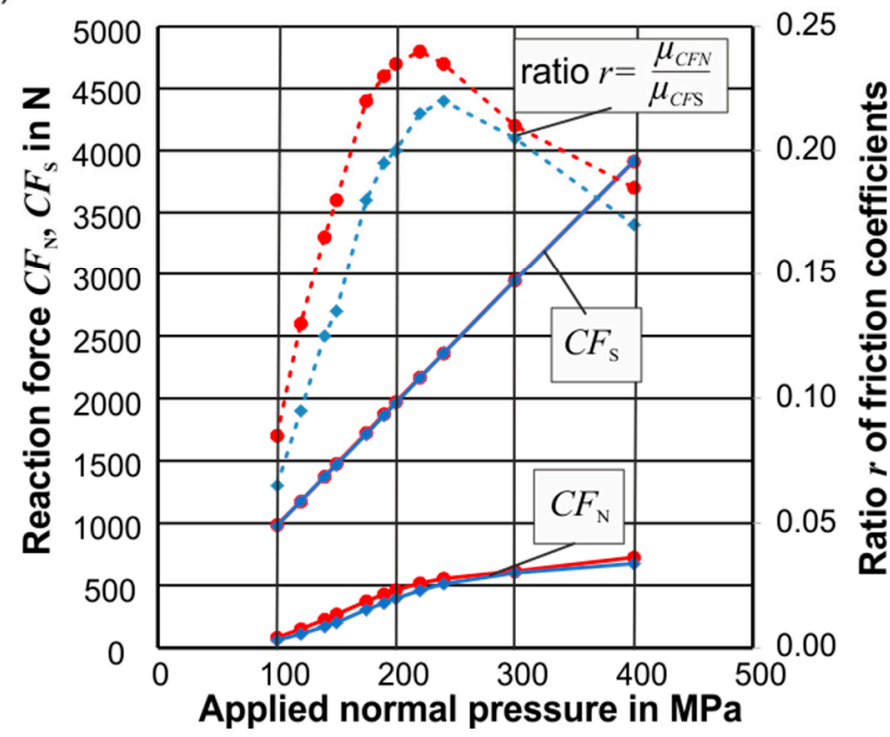

Twill woven,

$280 \mathrm{~g} / \mathrm{m}^{2}$,

$0 \% 90^{\circ}$ orientation

Plain woven,

$280 \mathrm{~g} / \mathrm{m}^{2}$

$0 \% 90^{\circ}$ orientation

Twill woven, $80 \mathrm{~g} / \mathrm{m}^{2}$,

$0 \% 90^{\circ}$ orientation
Twill woven,

$280 \mathrm{~g} / \mathrm{m}^{2}$

$-45^{\circ} \%+45^{\circ}$ orientation

Plain woven,

$280 \mathrm{~g} / \mathrm{m}^{2}$

$-45^{\circ} \%+45^{\circ}$ orientation

Twill woven,

$80 \mathrm{~g} / \mathrm{m}^{2}$

$-45^{\circ} \%+45^{\circ}$ orientation
Twill woven,

$280 \mathrm{~g} / \mathrm{m}^{2}$

$0 \% 90^{\circ}$ orientation

Twill woven,

$280 \mathrm{~g} / \mathrm{m}^{2}$,

$-45^{\circ} \%+45^{\circ}$ orientation

Figure 11. Numerical results of forces between sheet and fibers in tangential direction and friction coefficient at sticking state: (a) for $0^{\circ} / 90^{\circ}$ orientation of fibers; (b) for $-45^{\circ} / 45^{\circ}$ orientation of fibers; (c) comparison of both orientations. 
The results of the numerical investigations correspond to the experimental results shown in Figure 5. In the experimental and the numerical results, nearly no difference in the reduction of formability between both $280 \mathrm{~g} / \mathrm{m}^{2}$ fiber types can be seen. A significant influence of the orientation of the twill woven fibers to the loading direction could not be detected out from the simulations compared to the experimental results.

\section{Conclusions}

When forming fiber metal laminates, the fibers can be in contact with the metal blanks in case of:

- high fiber volume fraction,

- high contact pressures, which lead to a squeezing out of the resin (polymer), and

- forming with dry fibers and postponed injection.

Hereby, the formability of the blanks is reduced, as could be stated by the Nakazima experiments. From these experiments, it could be stated that the friction condition is the leading factor for the reduced forming limit. Furthermore, due to the characteristic strain distribution in blanks and the obvious imprints in the metal surface which are caused by high local normal loads, it could be seen that besides the coulomb friction, there is a kind of form-fit effect between the fabric and the metal blank. For the analysis, a numerical model was used. By using this numerical model, a detailed separation of the frictional and the interlocking effect could be realized. It could be seen that the influence on the movement by the interlocking can reach values up to $35 \%$ compared to the one caused by the coulomb friction.

Based on this research, it can be concluded that when using fabrics with high specific weights, a metal with higher yield stress should be used, so that the filling of the transition zones is postponed to higher normal loads. The form-fit effect, in cases where the filling reaches the same values, is more dominant for a high strength material than for a softer one. Additionally, to reduce the effect of the form-fit, high normal loads, as they can be achieved in radii, should be avoided when forming fiber metal laminates.

Author Contributions: Conceptualization, T.M.; Investigation, T.M.; Methodology, T.M., S.G. and N.B.K.; Project administration, N.B.K. and A.E.T.

Funding: This research was funded by DFG (Deutsche Forschungsgemeinschaft) within the project BE 5196/4-1.

Acknowledgments: The authors thank the supplier of the aluminum sheets Novelis S.A. Sierre (Switzerland) and the supplier of the matrix system Arkema S.A. (France).

Conflicts of Interest: The authors declare no conflict of interest. The funders had no role in the design of the study; in the collection, analyses, or interpretation of data; in the writing of the manuscript, and in the decision to publish the results.

\section{References}

1. Vlot, A. Glare: History of the Development of a New Aircraft Material; Kluwer Academic Publishers: Dordrecht, The Netherlands, 2004; ISBN 978-1-4020-0124-6.

2. Vogelesang, L.B. Development of a new hybrid material (ARALL) for aircraft structures. Ind. Eng. Chem. Prod. Res. Dev. 1983, 22, 492-496. [CrossRef]

3. Vogelesang, L.B.; Gunnink, J.W. ARALL: A materials challenge for the next generation of aircraft. Mat. Des. 1986, 7, 287-300. [CrossRef]

4. Miller, W.K. Metal-Plastic laminates for vehicle weight reduction. SAE Trans. 1980, 89, 481-490.

5. Toshiaka, S.; Hiroyushi, N.; Hoshihiko, K.; Takenobu, S.; Hiroo, T.; Masatsuno, K. Metal-Resin-Metal Sandwich laminates Suitbale for Use in Working. Patent EP0115103A1, 24 January 1983.

6. Soellart-Roelofsen, M.; Bottema, J. Metal-Polypropylene-Metal Laminate and Method of Making a Shaped Sheet Article of Such a Laminate. Patent EP0598428A1, 25 May 1994. 
7. Behrens, B.A.; Hübner, S.; Neumann, A. Forming Sheets of Metal and Fibre-reinforced Plastics to Hybrid Parts in One Deep Drawing Process. In Proceedings of the 11th ICTP 2014, Nagoya, Japan, 19-24 October 2014; Volume 81, pp. 1608-1613.

8. Dau, J.; Lauter, C.; Damerow, U.; Homberg, W.; Tröster, T. Multi-material systems for tailored automotive structural components. In Proceedings of the 18th ICCM, Jeju Island, Korea, 21-26 August 2011.

9. Wollmann, T.; Hahn, M.; Wiedemann, S.; Zeiser, A.; Jaschinski, J.; Modler, N.; Ben Khalifa, N.; Meißen, F.; Paul, C. Thermoplastic fibre metal laminates: Stiffness properties and forming behaviour by means of deep drawing. Arch. Civ. Eng. 2018, 18, 442-450. [CrossRef]

10. Lee, M.S.; Kim, S.J.; Lim, O.D. The effect process parameters on epoxy flow behavior and formability with CR340/CFRP composites by different laminating in deep drawing process. J. Mater. Process. Technol. 2016, 229, 275-285. [CrossRef]

11. Wang, Z.; Lauter, C.; Sanitther, C.B.; Frantz, M.; Tröster, T. Intrinsic-manufacturing of metal-FRP-hybrid structural automotive components by resin transfer moulding. In Proceedings of the 18th ICCS, Lisbon, Portugal, 15-18 June 2014.

12. Mennecart, T.; Werner, H.; Ben Khalifa, N.; Weidenmann, K.A. Developments and analyzes of alternative processes for the manufacturing of fiber metal laminates. In Proceedings of the MSEC 2018, College Station, TX, USA, 18-22 June 2018. [CrossRef]

(C) 2019 by the authors. Licensee MDPI, Basel, Switzerland. This article is an open access article distributed under the terms and conditions of the Creative Commons Attribution (CC BY) license (http:/ / creativecommons.org/licenses/by/4.0/). 